\section{Conflicts of interest in genetic counseling: addressing and delivering}

To the Editor: We read with interest the commentary by Stoll et al. ${ }^{1}$ entitled "Conflicts of Interest in Genetic Counseling: Acknowledging and Accepting," discussing conflicts of interest (COI) in genetic counseling pertaining to patient care. We agree that acknowledging and mitigating COI is imperative, not only among laboratory-based genetic counselors (lab-based GCs) but in any clinical environment. We also support the development of a publicly accessible database via the National Society of Genetic Counselors (NSGC)/American Board of Genetic Counseling, as suggested by Stoll et al. ${ }^{1}$ The importance of the topic addressed by their commentary is undisputed, which compels us, as practicing lab-based GCs actively engaged in patient care, to respond.

Stoll and colleagues' commentary implies a lack of acknowledgment and acceptance of COI in the field of genetic counseling. However, the NSGC has developed COI awareness resources including a Reference Sheet, Guiding Questions, and a Checklist to "help GCs recognize COI they may have, which in turn can give them confidence in assessing, disclosing, and managing this COI in their professional interactions" (http://www.nsgc.org/page/ethicsandcoi). The NSGC has put extensive effort into the development of these tools to assist not only lab-based GCs but any GC who may face COI through participation on advisory committees, acceptance of honoraria, or numerous other professional interactions with commercial entities.

There has been a limited number of blog posts, newspaper articles, and journal commentaries suggesting that lab-based GCs are too conflicted to provide patient care. ${ }^{1}$ However, there remains a paucity of evidence supporting these assertions. Such suppositions, when unsupported by peerreviewed data, diminish and distract from the excellent work accomplished by this growing sector of our profession. The field of genetic counseling demands that our everyday practice be informed by the available evidence, and the discussion regarding COI should be informed in the same way.

Stoll et al. ${ }^{1}$ contend that lab-based GCs may be conflicted between following practice guidelines and serving the interests of their for-profit employer (e.g., by providing pretest counseling). The authors point out that some insurers require non-lab-based pretest genetic counseling; however, this requirement was recently rescinded by one large payer (www.uhcprovider.com/content/ dam/provider/docs/public/policies/comm-medical-drug/genetictesting-hereditary-breast-ovarian-cancer-syndrome.pdf). Furthermore, our study, presented at the NSGC 2016 annual conference, demonstrated that for a cohort of 129 patients in a community clinic who underwent lab-based pretest genetic counseling, a recommendation was made to alter the genetic testing order $16 \%$ of the time. This resulted in the cancelation of testing for 9 of the 21 patients, because they either had a relative more appropriate for testing or had already tested negative. For an additional 4 of the 21 patients, the number of genes ordered was reduced, most often because of the discovery of a previously identified familial mutation after pedigree assessment by the lab-based GC. ${ }^{2}$

The authors further posit that the mere availability of posttest lab-based genetic counseling encourages nongenetics providers to order additional, unnecessary testing beyond their scope of practice. However, in a peer-to-peer consultation model involving lab-based GCs and breast surgeons, we found that test selection was altered in $21 \%$ of cases ( 37 of 170) after lab-based GC consultation. A substantial proportion of modified orders resulted in a reduction in the number of genes requested. ${ }^{3}$

Stoll et al. ${ }^{1}$ surmise that in the posttest setting, lab-based GCs may not be "as open to discussing the potential weaknesses and failures of tests as they would be if they were independently employed." Our experience contradicts this supposition. For example, early in our lab's history we offered hereditary cancer genetic testing but at the time were unable to disambiguate certain pathogenic variants in PMS2 from pseudogene sequences. Our lab-based GCs proactively communicated this limitation, which was documented in the test reports, to both clinicians and patients, instructing those for whom PMS2 analysis was indicated to obtain genetic testing elsewhere.

The authors propose that COI concerns may be mitigated by excluding lab-based GCs from providing direct patient care. However, it is important to recognize that lab-based GCs can play a critical role in providing clinical care at this time of provider scarcity (https://www.nsgc.org/page/workforce). Lab-based GCs have the capacity to substantially alleviate GC shortages because of the unique nature of the delivery model; service is typically provided through telephone- or video-based counseling. This enables genetic counseling to be conveniently provided to patients nearly anywhere, significantly reducing wait times and improving access to services.

In our laboratory, several measures have been implemented to mitigate COI with regard to genetic counseling services. First, all of our GCs, regardless of whether they interact directly with patients, are required to annually review the NSGC Genetic Counselor Code of Ethics, as a guiding code for our profession (http://www.nsgc.org/p/cm/ld/fid=12). Second, we disclose GC laboratory employment with our patients at three separate touch points: online at the time their appointment is scheduled, verbally at the start of the telephone genetic counseling session, and in writing as part of the clinical documentation sent to both patients and referring providers. 
Third, a flat pricing structure and re-requisition to additional genes at no additional charge eliminates the possibility of "upselling." Finally, GCs who are engaged in direct patient care are paid by salary, have no quotas, and receive no commission. We propose that implementation of such practices can significantly mitigate COI, and we invite others to adopt similar measures and/or contribute additional COI-mitigating practices to this important discussion.

Rather than restrict an entire segment of our profession from providing much-needed patient care, we propose including lab-based GCs as part of the solution. As noted in Practical Genetic Counseling for the Laboratory, "Patient welfare is primary for all genetic counselors regardless of work setting." 4 We hope this discussion will act as a catalyst to further explore this issue. Such exploration will allow labbased GCs to continue addressing COI, help ameliorate the critical shortage of GCs, and continue delivering professional, patient-centered care.

\section{DISCLOSURE}

The authors, Daniela lacoboni, Kate Lynch, Dr. Edward D. Esplin, and Dr. Robert L. Nussbaum, are employees and shareholders of Invitae Corp., a publicly traded commercial laboratory.

Daniela Iacoboni, $M S^{1}$, Kate Lynch, $M S^{1}$, Edward D. Esplin, $M D, P h D^{1}$ and Robert L. Nussbaum, $M D^{1}$

${ }^{1}$ Invitae Corp, San Francisco, California, USA. Correspondence: Daniela Iacoboni (daniela.iacoboni@invitae.com)

\section{REFERENCES}

1. Stoll KA, Mackison A, Allyse MA, Michie M. Conflicts of interest in genetic counseling: acknowledging and accepting. Genet Med 2017;19: 864-866.

2. Lynch K, lacoboni D, Nussbaum R, Esplin E, Czape K, Kurz R. A novel approach to lab-based clinical genetic counseling. National Society of Genetic Counselors Annual Education Conference, Seattle, WA, 28 September-1 October 2016.

3. O'Leary E, Kurz RN, Ekstein $T$, et al. Addition of a remote genetic counselor to the breast specialist's team improves clinical decisionmaking. 2017 National Society of Genetic Counselors Annual Education Conference, Columbus, OH, 13-16 September 2017.

4. Reiser C. Foreward. Goodenberger ML, Thomas BC, Kruisselbrink T, (eds) Practical Genetic Counseling for the Laboratory. Oxford University Press: New York, 2017.

(i) (-) $€$ This work is licensed under a Creative Commons Attribution-NonCommercial-NoDerivs $\quad 4.0$ International License. The images or other third party material in this article are included in the article's Creative Commons license, unless indicated otherwise in the credit line; if the material is not included under the Creative Commons license, users will need to obtain permission from the license holder to reproduce the material. To view a copy of this license, visit http://creativecommons.org/licenses/ by-nc-nd/4.0/

(c) The Author(s) 2018

Advance online publication 4 January 2018. doi:10.1038/gim.2017.234 